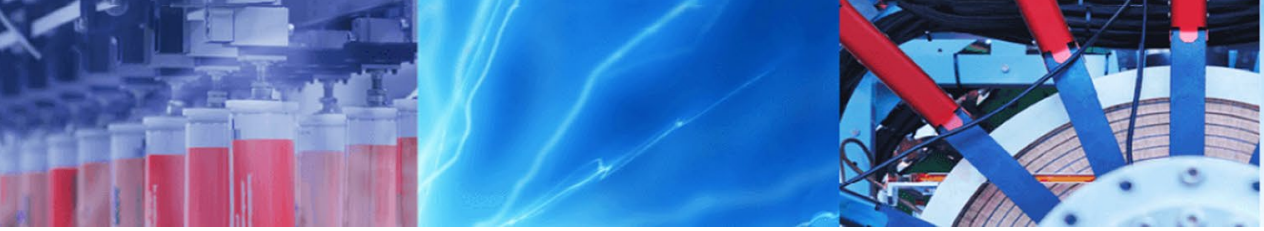

Research Article

\title{
Understanding the characteristics of rapid intensity changes of Tropical Cyclones over North Indian Ocean
}

\author{
Raghu Nadimpalli ${ }^{1}$. Shyama Mohanty ${ }^{1} \cdot$ Nishant Pathak $^{1} \cdot$ Krishna K. Osuri $^{2} \cdot$ U. C. Mohanty ${ }^{1} \cdot$ \\ Somoshree Chatterjee ${ }^{1}$
}

Received: 31 August 2020 / Accepted: 21 December 2020

(C) The Author(s) 2021, corrected publication 2021 OPEN

\begin{abstract}
North Indian Ocean (NIO), which comprises of Bay of Bengal (BoB) and Arabian Sea (AS) basins, is one of the highly potential regions for Tropical Cyclones (TCS) in the world. Significant improvements have been achieved in the prediction of the movement of TCs, since the last decade. However, the prediction of sudden intensity changes becomes a challenging task for the research and operational meteorologists. Hence, the present study focuses on finding the climatological characteristics of such intensity changes over NIO regions. Rapid Intensification (RI) is defined as the 24-h maximum sustained surface wind speed rate equal to 30 knots $\left(15.4 \mathrm{~ms}^{-1}\right)$. The results suggest that the TCs formed over the NIO basin are both seasonal and basin sensitive. Since 2000, a significant trend is observed in RI TCs over the basin. At least one among three cyclones getting intensified is of RI category. More number of RI cases have been identified in the BoB basin than the AS. The post-monsoon season holds more RI and rapid decay cases, with $63 \%$ and $90 \%$ contribution. Most of the TCs are attaining RI onset in their initial stage. Further, India is receiving more landfalling RI TCs, followed by Bangladesh and Oman. The east coast of India, Tamil Nadu, and Andhra Pradesh are the most vulnerable states to these RI TCs. The cyclogenesis locations associated with RI cases hold higher moisture, and sea surface temperature as compared to the Non-RI cases.
\end{abstract}

Keywords Tropical cyclones · Rapid intensification · North Indian ocean

\section{Introduction}

North Indian Ocean (NIO) is a highly potential region for Tropical Cyclones (TCs). The Indian coastline is a prone area to TCs and is the worst affected region globally, having a coastline of $7516 \mathrm{~km}[12]$. Thirteen coastal states/ UTs encompass 84 coastal districts affected by cyclones [12]. About 7\% of the global TCs are formed over the NIO basin, comprised of the Bay of Bengal (BoB) and Arabian Sea (AS) [10]. The NIO coastal countries are much populated and thus more concerned [10]. Generally, NIO experiences $\sim 5-6$ systems intensified to TC with sustained wind magnitude of $>34$ knots or more [10]. In the NIO, BoB reports the highest number of tropical cyclones, which is almost five times higher than the AS [25]. Past reports confirmed that the most deadly TCs and highest catastrophe and death tolls occurred in the NIO basin, especially over the BoB [10].

With the advancements in the dense observational network such as in-situ, satellite, radar, and other remote sensed platforms, the TC movement's prediction accuracy has been improved from the last few decades [12]. Significant improvements have been achieved in the prediction of the track of TC since the previous few years due

$\triangle$ Raghu Nadimpalli, raghu.met2012@gmail.com | ${ }^{1}$ School of Earth Ocean and Climate Sciences, Indian Institute of Technology Bhubaneswar, Argul, Odisha 752050, India. ${ }^{2}$ Department of Earth and Atmospheric Sciences, National Institute of Technology Rourkela, Rourkela, Odisha 769008, India. 
to the advancements in numerical weather prediction models and data assimilation techniques over the NIO basin $[6,7,18,20,21,23], 2015,2017,[14-16]$,Mohanty et al., 2015,2019, [2]. However, the intensity prediction is still a challenging task for the operational and research community due to their intensity changes such as rapid intensification (RI) ${ }^{1}$ and rapid decay (RD) ${ }^{2}$ over the basin $[11,26],[27]$. The operational intensity forecast error for the intense TCs (wind speed $>48$ knots) is considerably large over the NIO region [12].

Recent studies have addressed the improving prediction of intensity changes through various methods such as the use of high-resolution modeling systems $[1,3,6$, 22], vortex in Bhalachandran itialization [2], data assimilation $[16,19]$. However, these studies are mostly limited to the individual TCs or very few cases. Moreover, due to the increasing temperatures globally, TCs pose a severe hazard to the coastal regimes [10], [9]. The BoB has become more conducive to TC intensification due to increased upper ocean heat content and sea surface temperature (SST) [10].

The best possible way to approach this problem is to analyze the history of tropical cyclones in the NIO basin. Therefore, it is crucial to understand if, and why, there are observed upward trends in TC intensification rates. It provides an opportunity to understand the behavior of their pathways, intensity, and a possible way to evaluate the cyclone hazard. Accurate TC intensity prediction is vital to forecasting because early guidance of the strength of a TC and its rainfall distribution can save lives and reduce property damages and is a research interest. So, an attempt has been made to analyze the climatological characteristics of $\mathrm{TCs}$, which helps in understanding the RI and RD nature of TCs.

\section{Data and methodology}

In this study, the International Best Track Archive for Climate Stewardship (IBTrACS) data [8] have been considered for getting cyclogenesis in the BoB and the AS regions 1945-2018. Besides, high temporal resolution (at 3hourly) best track archival from the Regional Specialized Meteorological Centre (RSMC), published by the India Meteorological Department (IMD), for the period 1982 to 2018 (37 years) [available at www.rsmcnewdelhi.imd. gov.in] has been considered to identify the accurate RI

\footnotetext{
${ }^{1}$ Rapid intensification is defined as an increase of 30 knots intensity change in maximum sustained wind in a $24 \mathrm{~h}$ period [22].

2 Rapid Decay is defined as a decrease of 25 knots intensity change in maximum sustained wind in a $24 \mathrm{~h}$ period [5].
}

and RD stages of the TCs. Further, the European Centre for Medium-Range Weather Forecast (ECMWF) Reanalysis $5^{\text {th }}$ Generation (ERA5) data at a spatial resolution of $0.25^{\circ} \times 0.25^{\circ}$ degree and temporal resolution of $1 \mathrm{~h}$ for the 1982- 2018 period is used to analyze the characteristics associated with TCs.

\section{Results and discussions}

\subsection{Cyclogenesis}

A TC is termed as an anti-clockwise non-frontal synopticscale low-pressure circulation system over tropical oceans with organized convection in the northern hemisphere [10]. There is no universally accepted definition for tropical cyclogenesis. According to Ritchie and Holland [24], cyclogenesis is defined as the sequence of physical processes such as a warm core, cyclonic vortex with high wind speed near the surface. Later, [17] defined genesis as when the Maximum Sustained Wind (MSW) reaches the depression stage. Hence, in this present study, we considered the depression stage as the cyclogenesis. Figure 1 shows the cyclogenesis points of TCs formed during the pre-monsoon and post-monsoon season, respectively. The grid size is $0.5^{\circ} \times 0.5^{\circ}$ for the period $1945-2018$. From the figure, it can be seen that the number of grid points with cyclogenesis is significantly large for the BoB as compared to the AS during both the seasons of the pre-monsoon and post-monsoon. During the post-monsoon season, the spatial distribution of cyclogenesis grid points is more concentrated than that of the pre-monsoon and has an extension of $100^{\circ} \mathrm{E}$ longitude. Thus, the post-monsoon season receives more TCs over the BoB basin than pre-monsoon season. A grid maximum of 2 cyclogenesis points lies and falls under the $B o B$ basin, shows that the $B o B$ region is more conducting than the AS region.

Latitude-wise and longitude-wise, genesis point distributions during the pre-monsoon and post-monsoon seasons are also analyzed. A few latitude and longitudinal regions have embraced more frequency of cyclogenesis than others. During the pre-monsoon season, 68 cases out of 103 are formed between $82^{\circ}$ and $92^{\circ}$ E longitudes. Similarly, the latitudes $9^{\circ} \mathrm{N}-15^{\circ} \mathrm{N}$ favor the genesis of 74 cases out of a total of 103 in the pre-monsoon season. However, the latitudinal belt $11^{\circ} \mathrm{N}-13^{\circ} \mathrm{N}$ prefers the most. Therefore, it can be concluded that the active TC cyclogenesis region ranges between $82^{\circ}$ and $92^{\circ} \mathrm{E}$ and $9^{\circ}$ and $15^{\circ} \mathrm{N}$ during the pre-monsoon season. During the post-monsoon season, longitudes from $84^{\circ} \mathrm{E}$ to $90^{\circ} \mathrm{E}$ hold $51 \%$ of total cases $(193$ cases out of 374 ), and the longitudes from $84^{\circ} \mathrm{E}$ to $86^{\circ} \mathrm{E}$ have a maximum number of cases, i.e., 62 . In the case of latitudes, $76 \%$ of TCs are formed between $7^{\circ} \mathrm{N}$ and $13^{\circ} \mathrm{N}$. 

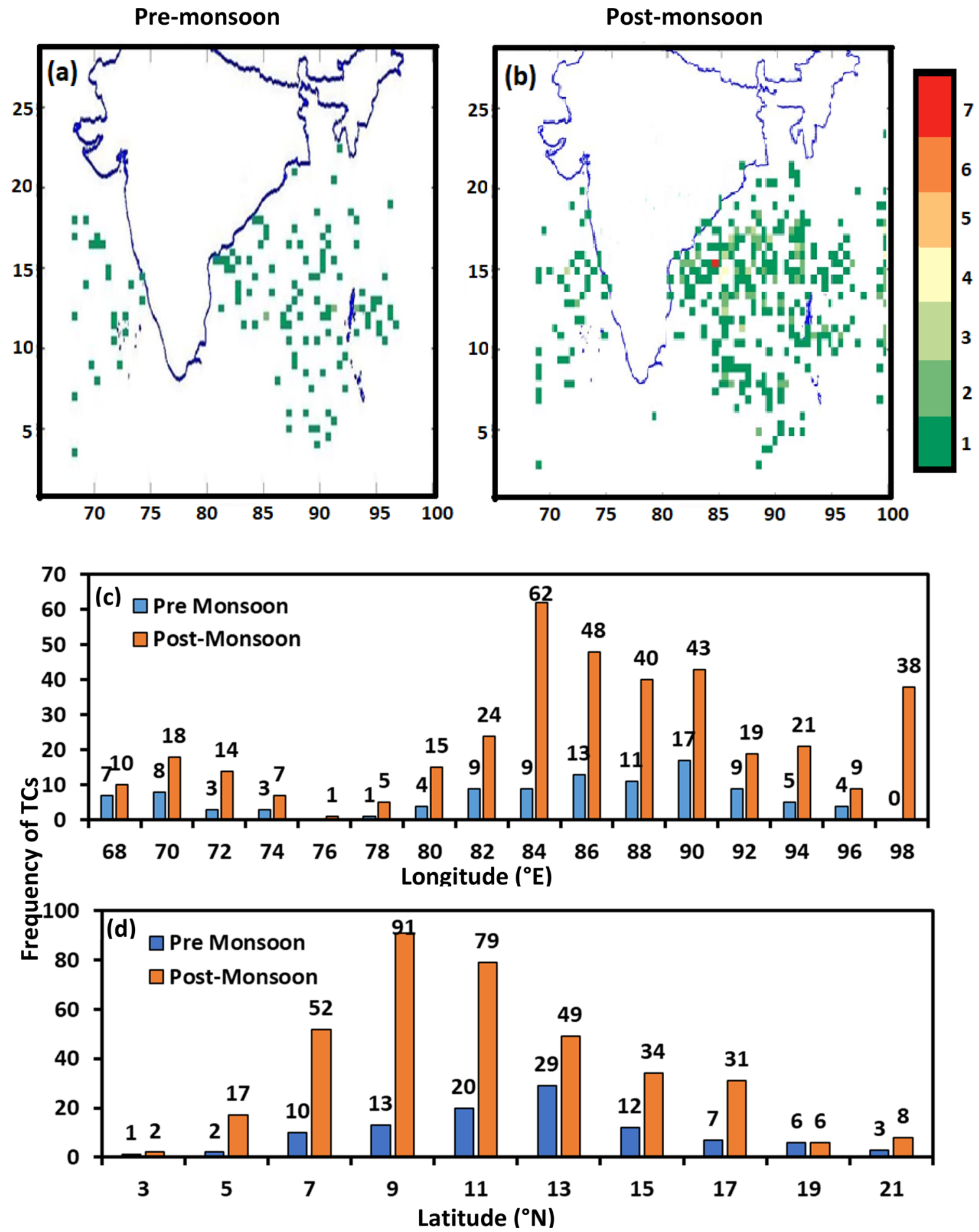

Fig. 1 Spatial distribution of cyclogenesis over NIO basin during a Pre-monsoon and b Post-monsoon seasons. $\mathbf{c}$ Longitudinal distribution of cyclogenesis for both the seasons. $\mathbf{d}$ same as $\mathbf{c}$ but represents latitudinal distribution

The latitudes of $9^{\circ} \mathrm{N}$ to $11^{\circ} \mathrm{N}$ hold maximum cases, i.e., 91 . During the post-monsoon season, the most active region for cyclogenesis lies in the area $82^{\circ} \mathrm{E}-90^{\circ} \mathrm{E}$ and $7^{\circ} \mathrm{N}-17^{\circ} \mathrm{N}$. This analysis also concludes that the BoB basin is more vulnerable to TC formation than the AS.

\subsection{Rapid intensity changes of TCs}

The cyclogenesis of RI and Non-RI cases have been plotted in Fig. 2a, b, respectively. From the figure, it is seen that $\mathrm{BoB}$ is holding more $\mathrm{RI}$ cases compared to the AS. The 

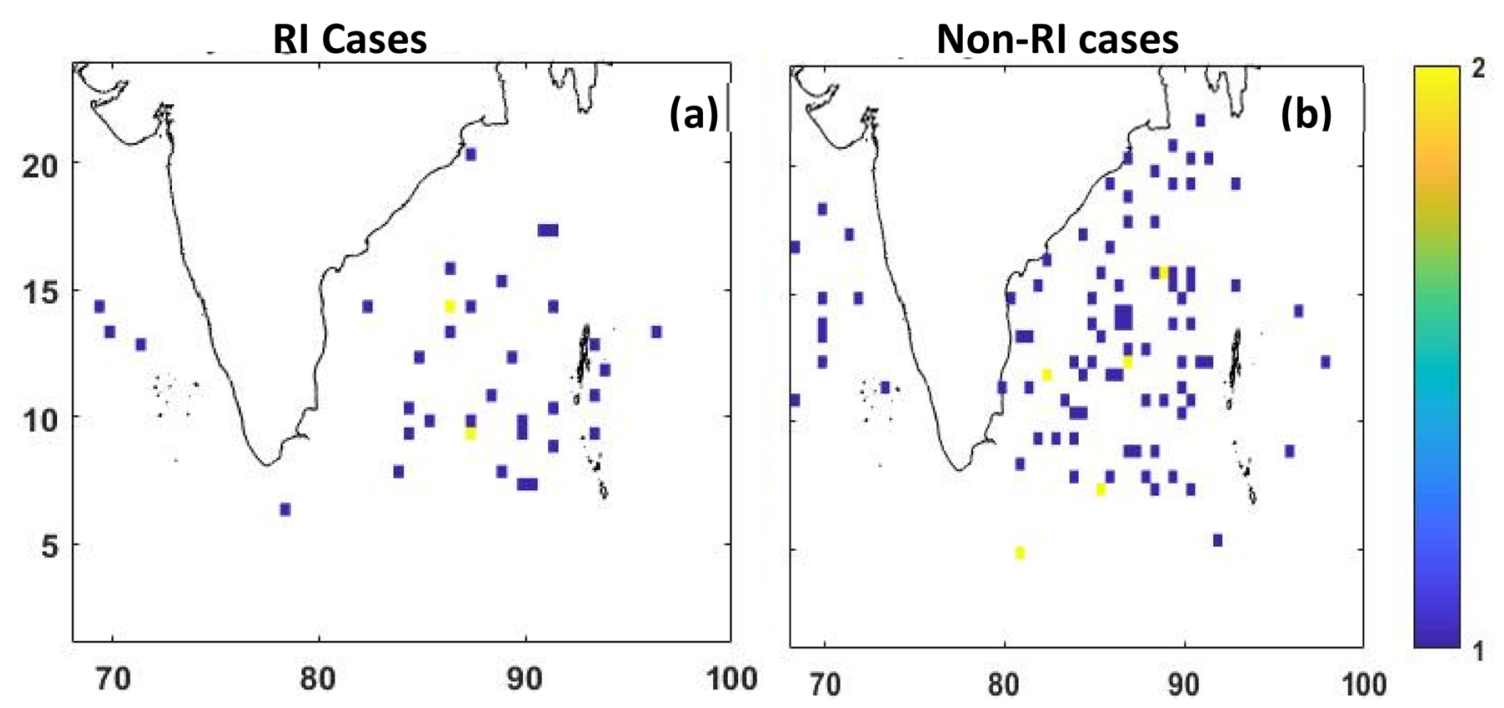

(c) Trend of RI cases (1982-2018)

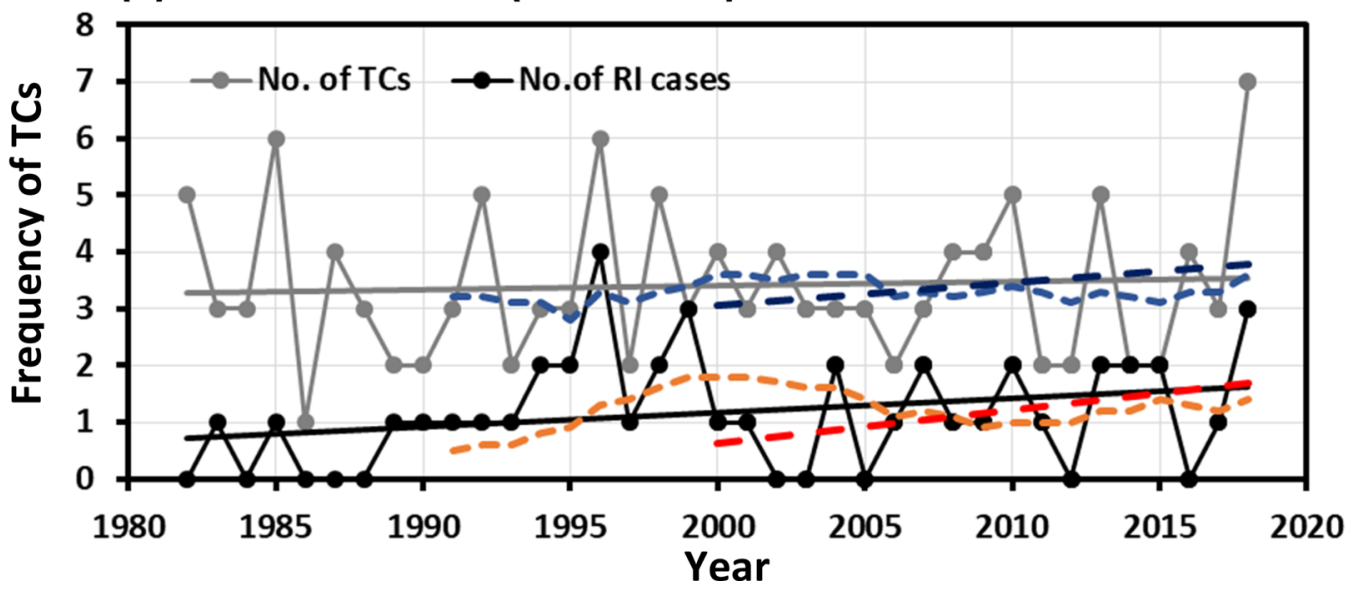

Fig. 2 Spatial distribution of cyclogenesis of a rapid intensified cases and $\mathbf{b}$ non-rapid intensified cases over NIO basin. $\mathbf{c}$ Distribution of TC (gray) and RI (black) cases for the period 1982-2018. The linear trend lines at $95 \%$ significant level for the whole period and

latitudinal and longitudinal analysis reveals that RI occurrence is more between $9^{\circ} \mathrm{N}-18^{\circ} \mathrm{N}$ and $84^{\circ} \mathrm{E}-93^{\circ} \mathrm{E}$ with a contribution of $92 \%$ and $93 \%$, respectively. The AS basin contributed only five RI TCs since 1982. Figure 2c shows the inter-annual changes in RI TCs over the NIO region. The trend analysis shows that the number of RI cases are marginally increasing at a slower rate during 1982-2018 (Blue line). The ten-year moving average of total TC number and RI-TCs showed a slight decrease in the number total TC number and a similar trend in RITC numbers. However, since 2000, the RI TCs exhibited a significant rise in the trend Fig. 2c. The yearly analysis revealed that the RI TCs are often regular since 2006 except in 2012 and 2016. In the years 2018 and 2019, a total of 3 and 5 cases have exhibited RI. For the years before 2000 , the RI cases trend is not significant. Though the number of TC occurrence is since the year 2000 are shown in blue and red dotted lines, respectively. Ten year moving average of TC and RI cases displayed in light blue and Orange dashed lines, respectively

high, the RI TCs are significantly less ( 0.8 out of 4$)$. The correlation between the number of occurrence of TC numbers and $\mathrm{RITCs}$ occurrence is 0.34 as a whole. But since 2000 , the correlation is 0.36 . These statistics have clearly showed that a higher intensification rate was observed recently $[4,10]$.

Figure 3 shows the TC distribution for both RI and RD cases, along with non-intensity changes. Figure 3a shows that out of 31 pre-monsoon season cases, 12 are of RI cases, and 19 are of Non-RI cases. In the post-monsoon season, out of 86 cases, 32 are Rl cases, and the rest are Non-RI cases. In the case of RD Fig. 3b, only one case is observed out of 31 cases, and the remaining are Non-RD cases. It is to be noted that only those cases which are rapidly decayed over the ocean are considered. In the postmonsoon season, out of 86 cases, 11 cases have exhibited 


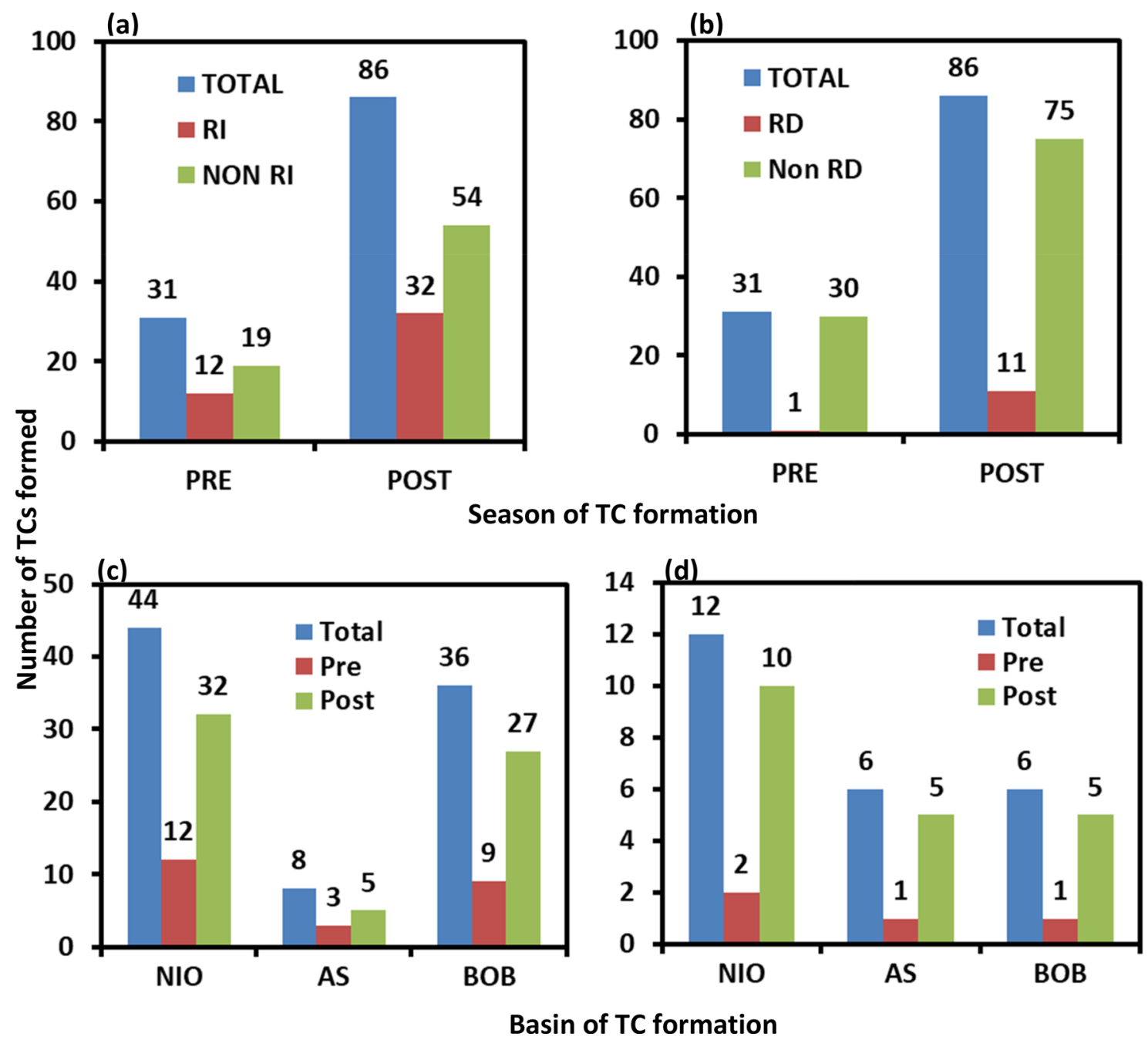

Fig. 3 a Number of RI and Non-RI cases during pre- and post-monsoon seasons. $\mathbf{b}$ same as a but for RD cases. The number of $\mathbf{c}$ RI and $\mathbf{d}$ RD cases formed over various basins

RD. Also, the RD cases are less against the number of RI cases for both seasons. A similar analysis has been carried out for RI and RD cases' seasonal distribution over various basins and has been shown in Fig. 3c, d. In the NIO region, out of $44 \mathrm{RITCs}$, eight are of pre-monsoon season, and 36 are of post-monsoon season. The post-monsoon season shows higher proximity of RI TC occurrence $(81 \%)$ in the $\mathrm{NIO}$ region against the pre-monsoon season (18\%). Over the BoB basin, out of a total of $36 \mathrm{RITCs}, 75 \%$ of TCs are formed during the post-monsoon season, while the premonsoon season has contributed $25 \%$.

On the other hand, the AS basin exhibited $63 \%$ and $37 \%$ for the post-monsoon and pre-monsoon seasons, respectively. In RD TCs, the NIO has contributed mainly by the post-monsoon season (83\%), whereas the pre-monsoon has contributed $17 \%$. The statistics are consistent with the $\mathrm{RI}$ statistics and followed the same trend. At the same time, the basin wise analysis revealed that the same number of cases had been observed from both the AS and the BoB basins. The pre-monsoon and post-monsoon seasons exhibited the same number of cases $(17 \%$ and $63 \%$ for pre-monsoon and post-monsoon seasons). This analysis shows that irrespective of TC behavior (RI/RD), the postmonsoon season receives more cases. Similar statistics are identified for the BoB basin too.

Further, the time required to attain the RI onset phase is computed and showed in Fig. 4. Most of the TCs exhibit $\mathrm{RI}$ during $24-72 \mathrm{~h}(66 \%)$ in the pre-monsoon season, and $0-24$ and above $72 \mathrm{~h}$ exhibited $17 \%$ each. But during the post-monsoon season, the Rl onset is observed for $24-48 \mathrm{~h}$ (44\%) followed by $0-24 \mathrm{~h}(31 \%)$ since cyclogenesis. It reveals that irrespective of the season, $\mathrm{Rl}$ is occurring during $24-72 \mathrm{~h}$ since cyclogenesis. A similar analysis has been carried out basin wise Fig. 4c-d. The study revealed that the $\mathrm{Rl}$ onset is more likely to happen within $48 \mathrm{~h}$ from the genesis time in both the basins. In the BoB basin, most TCs 

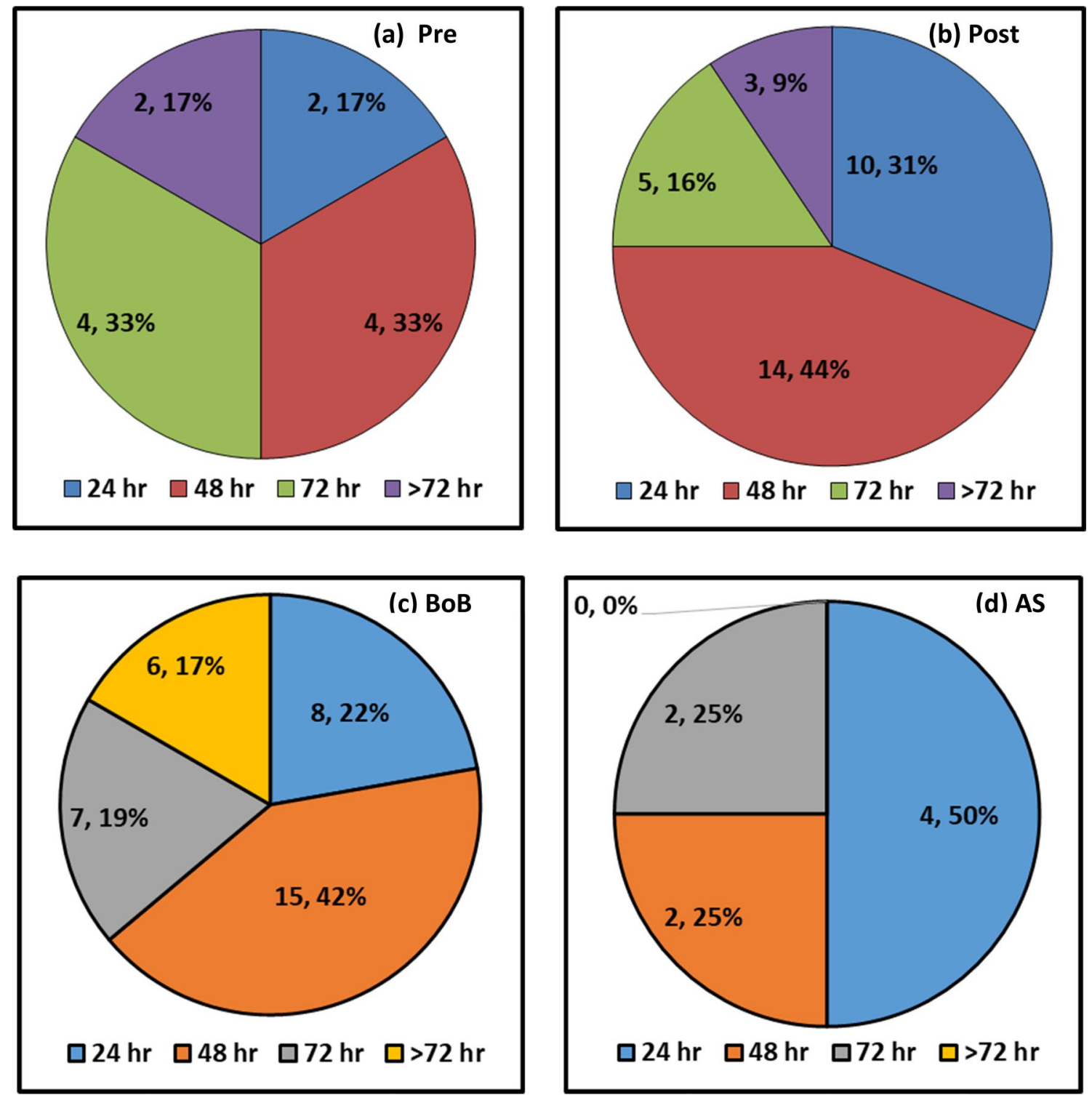

Fig. 4 Time required (hours) to exhibit rapid intensification from cyclogenesis in a pre-monsoon and $\mathbf{b}$ post-monsoon seasons. $\mathbf{c}-\mathbf{d}$ is same as $\mathbf{a}-\mathbf{b}$ but for $\mathbf{c}$ BoB and $\mathbf{d}$ AS basins

are attaining the RI phase within $48 \mathrm{~h}(42 \%)$, while the AS exhibited the same in $24 \mathrm{~h}(50 \%)$. Though the number of cyclones reaching the $\mathrm{Rl}$ phase after $72 \mathrm{~h}$ is less in number, they are prone to coastal regions close to landfall. It is also to be noted that the average time taken to make landfall after cyclogenesis over the NIO region is $72-120 \mathrm{~h}$ [13]. Therefore, the cyclones reach the RI phase after $72 \mathrm{~h}$ need more attention as the cyclone gale wind poses a severe threat to coastal regimes in various aspects. The analysis infers the RI onset mostly occurs in the initial stages of TCs in the open ocean.

It is also very much essential to see the RITCs that strike $\mathrm{NIO}$ rim counties. Hence the RITCs that made landfall over various countries and coastal states of India are analyzed and shown in Fig. 5. The analysis has shown that India experiences more RI TCs Fig. 5a, i.e., 54\%. The secondary peak is observed for Bangladesh and Oman (10\% each). Further, the analysis is focused on India's various coastal states as they are more vulnerable to RI TCs. The eastern coastal state of Tamil Nadu experiences major RI TCs, i.e., $33 \%$, followed by Andhra Pradesh (29\%). The eastern states experience $90 \%$ of RI TCs as compared to the west coast $(10 \%)$. On the west coast, Gujarat is the only state that has experienced land falling of RI TCs.

The meteorological conditions (such as moisture availability, vorticity, divergence, sea surface temperature, and moist static energy) are analyzed to understand the characteristic changes associated with RI and non-RI cases. It 
Fig. 5 a Distribution of RITCS over various rim countries of NIO basin. b Same as a but for different coastal states of India
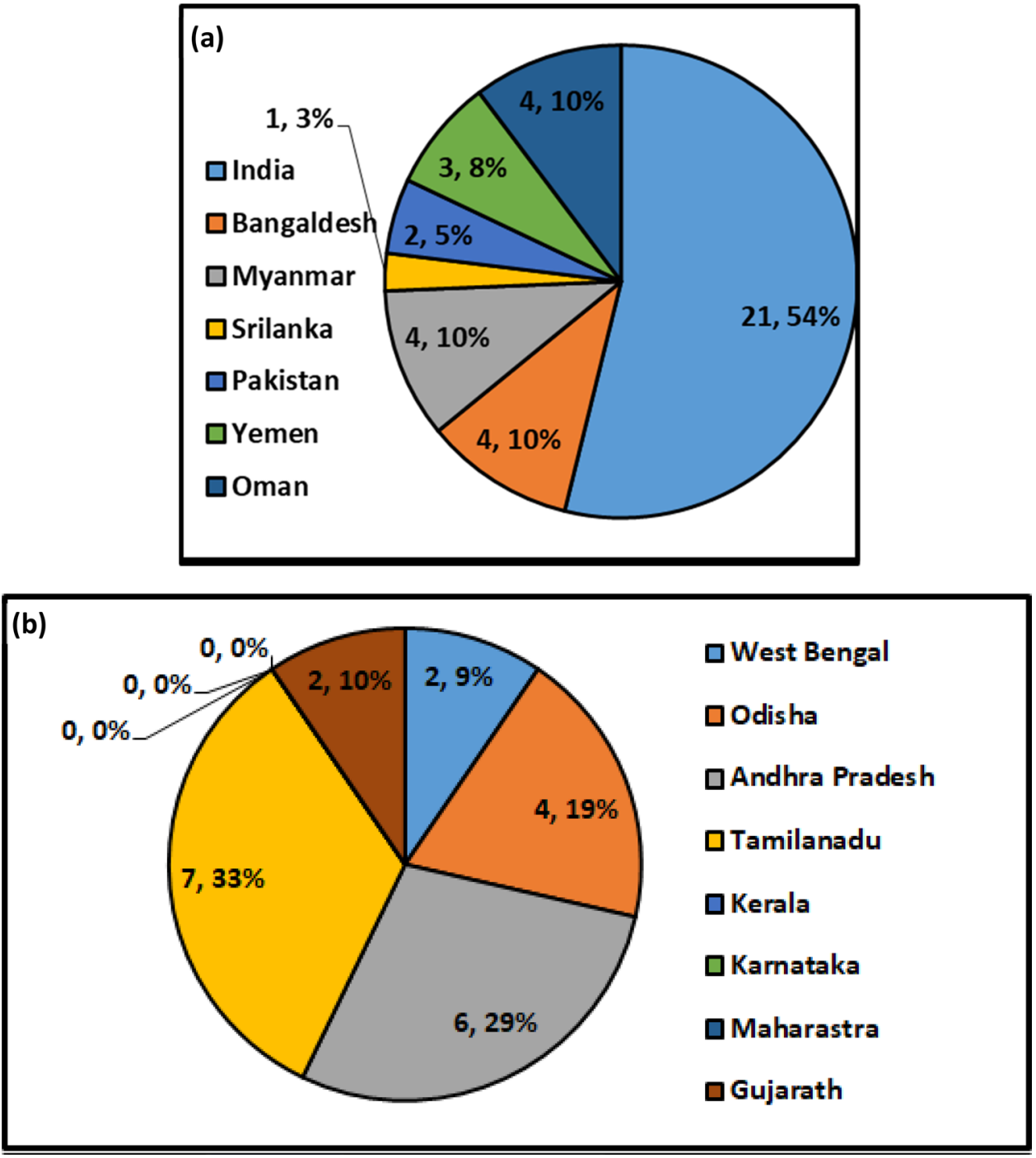

is to be noted that the analysis has been carried out at the time of genesis. Figure 6 shows the anomaly of the vorticity for RI and Non-RI events during the pre-monsoon and post-monsoon periods. The black dots in Fig. 6 represent the $90 \%$ significance level. From the Non-RI case, it can be seen that the vorticity anomaly distribution is similar for both seasons Fig. 6a, c. The RI cases from both the seasons exhibited notable variations (positive and negative anomalies) over the Bay Fig. 6b, d. However, the post-monsoon $\mathrm{RI}$ case has shown significant positive anomalies compared to the pre-monsoon RI event (negative) around the Andaman Sea. This is the region where maximum $\mathrm{RI}$ genesis points are observed.

Figure 7 shows the spatial distribution of specific humidity anomalies over the NIO region. Figure $7 a-b$ illustrates that 0-1 $\mathrm{g} / \mathrm{kg}$ humidity anomalies are more significant for the pre-monsoon Non-RI case. In contrast, the pre-monsoon $\mathrm{Rl}$ case has shown abundant moisture availability (more than $3 \mathrm{~g} / \mathrm{kg}$ ) that spreads across the bay with more significance in lower and upper $\mathrm{BoB}$ regions. On the other hand, the post-monsoon Non-RI case exhibited lesser changes in the anomaly and mostly the same to the climatology. However, the post-monsoon RI cases have shown the significant moisture spread of $2-3 \mathrm{~g} / \mathrm{kg}$ at $13^{\circ} \mathrm{N}-15^{\circ} \mathrm{N}$ and $84^{\circ} \mathrm{E}-86^{\circ} \mathrm{E}$ region and well correlated with the location of occurrence of higher RI TC numbers. Further, the low-level convergence and upper-level divergence were also analyzed and presented in Figs. 8, 9. From Fig. 8a, c, it can be observed that the distribution of convergence anomaly is similar for Non-RI cases during both the seasons. However, both seasons could exhibit an equal spread of significant regions over the Bay of Bengal for RI cases. The tangential winds over the boundary layer are intensified by the convectively induced inflow in the low levels, which have higher convergence rates in a cyclone's bottom levels [22]. Therefore, the positive anomalies could support RI onset when TCs pass over the region of higher vorticities. The divergence analysis also revealed the same. 

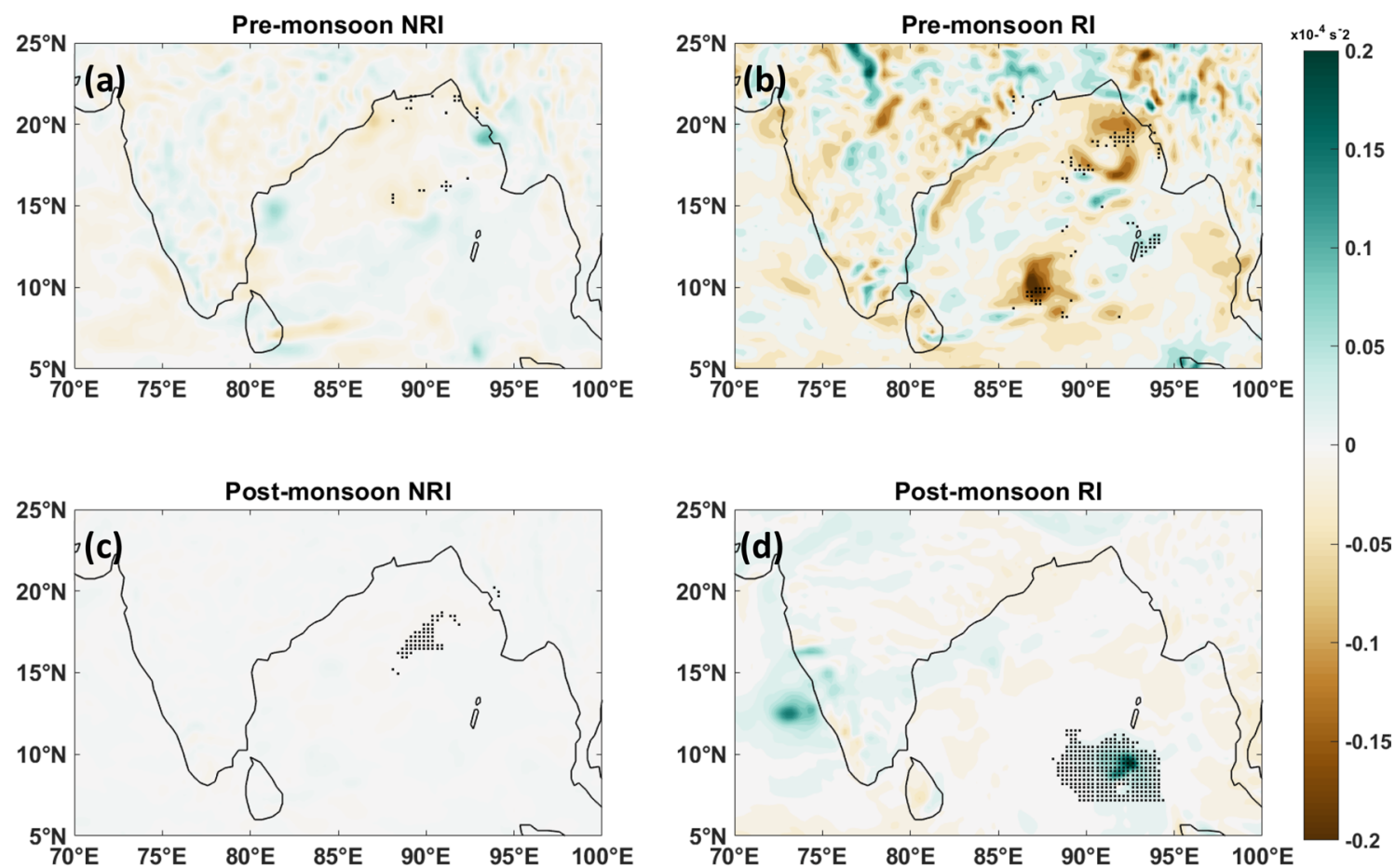

Fig. 6 a Vorticity anomaly for Pre-Monsoon Non RI events. b, c and d are same as a but for Pre-Monsoon RI, Post-Monsoon Non RI and PostMonsoon Rl events, respectively. The black dots in the figure represents the $90 \%$ significant level
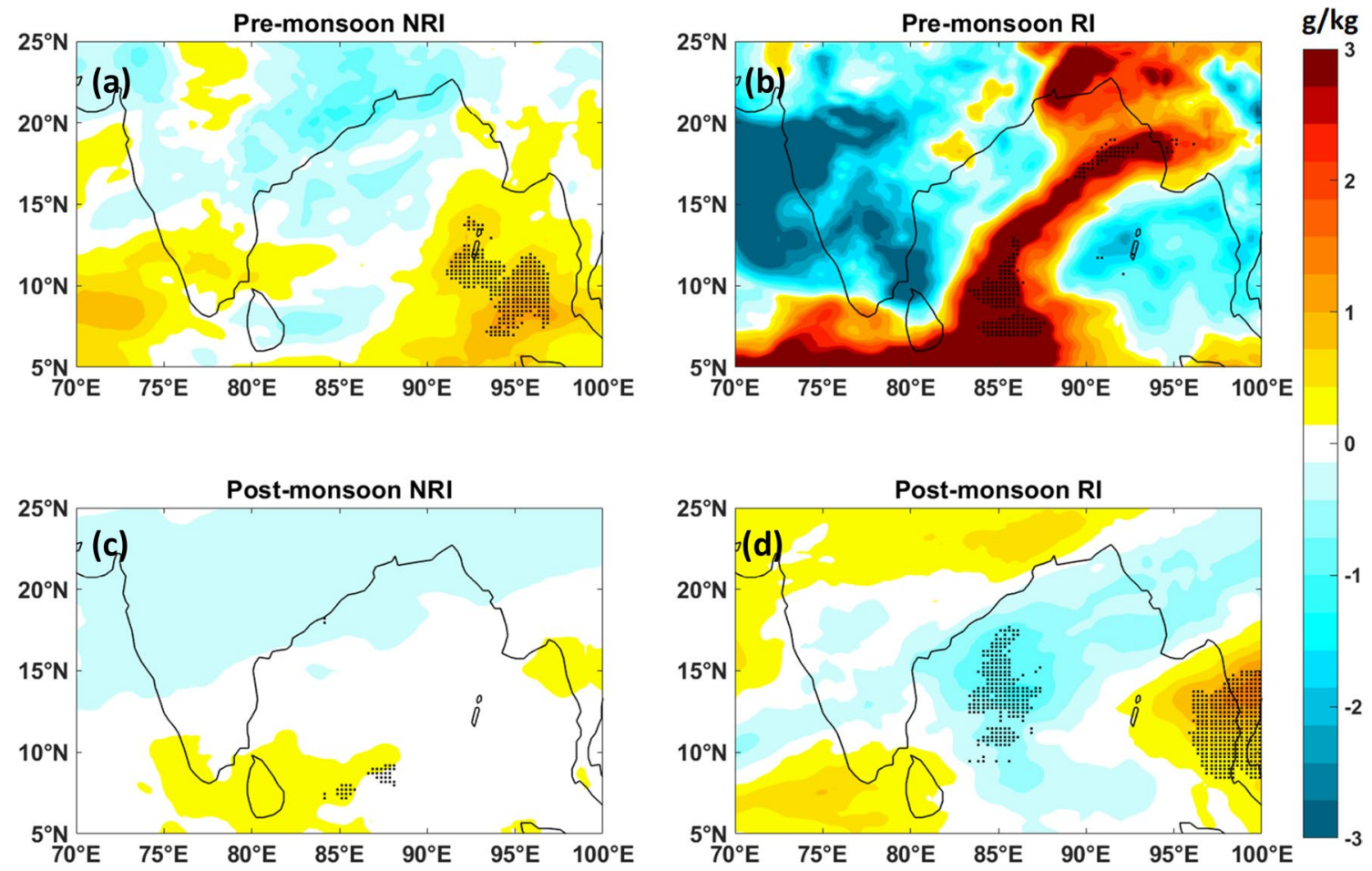

Fig. 7 Same as Fig. 6 but for specific humidity anomaly

\section{SN Applied Sciences}



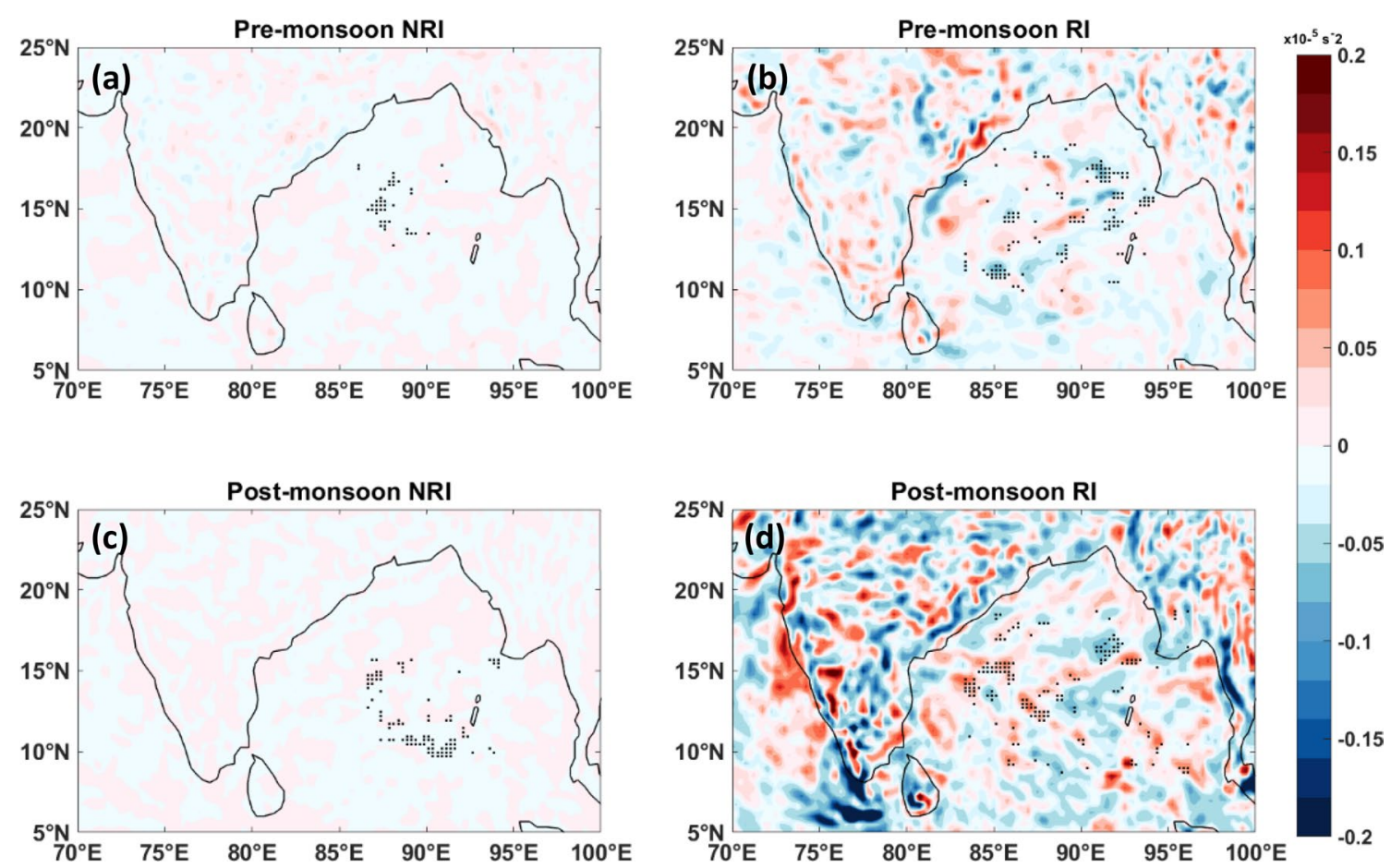

Fig. 8 Same as Fig. 6 but for low level convergence anomaly
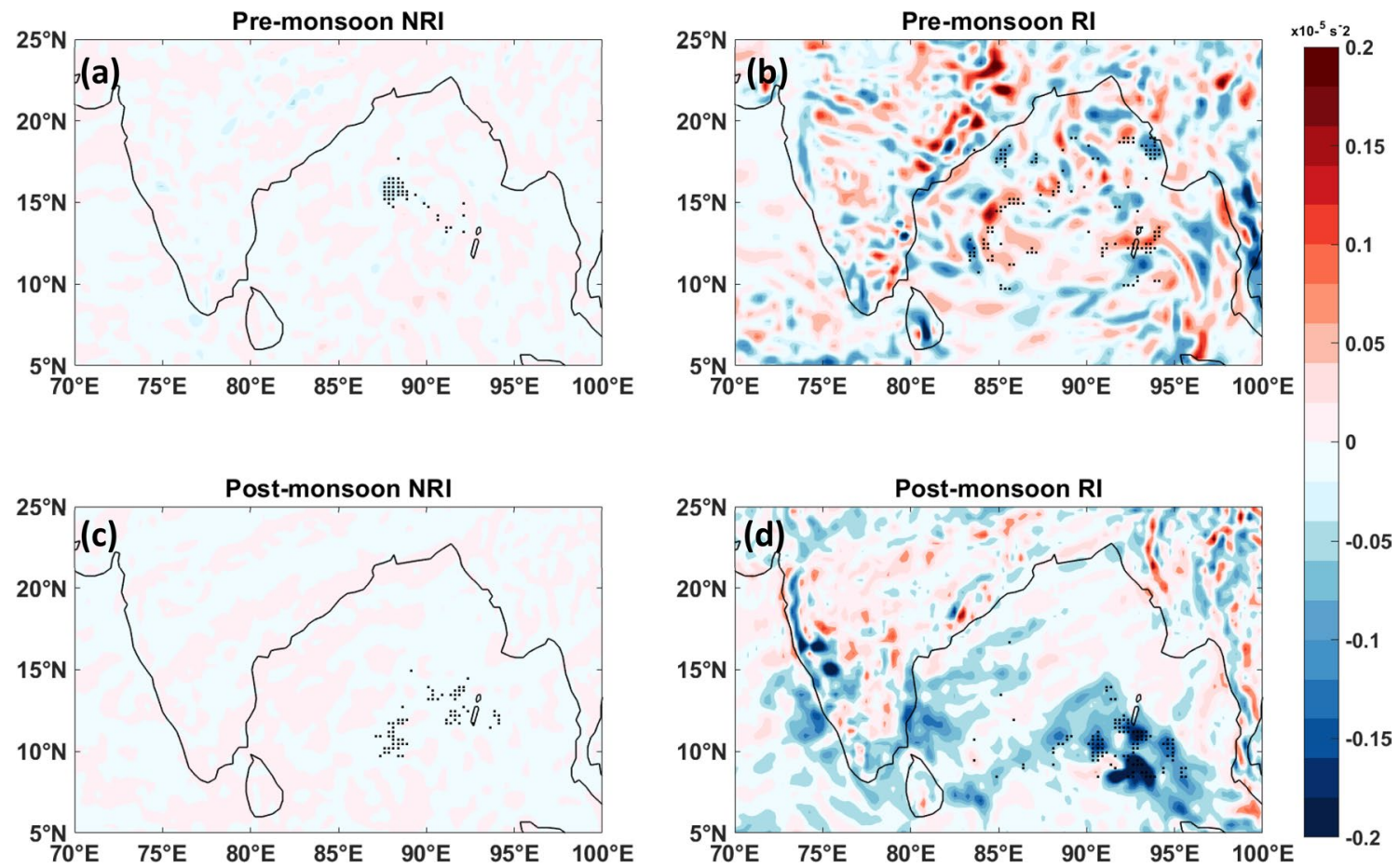

Fig. 9 Same as Fig. 6 but for upper level divergence anomaly 

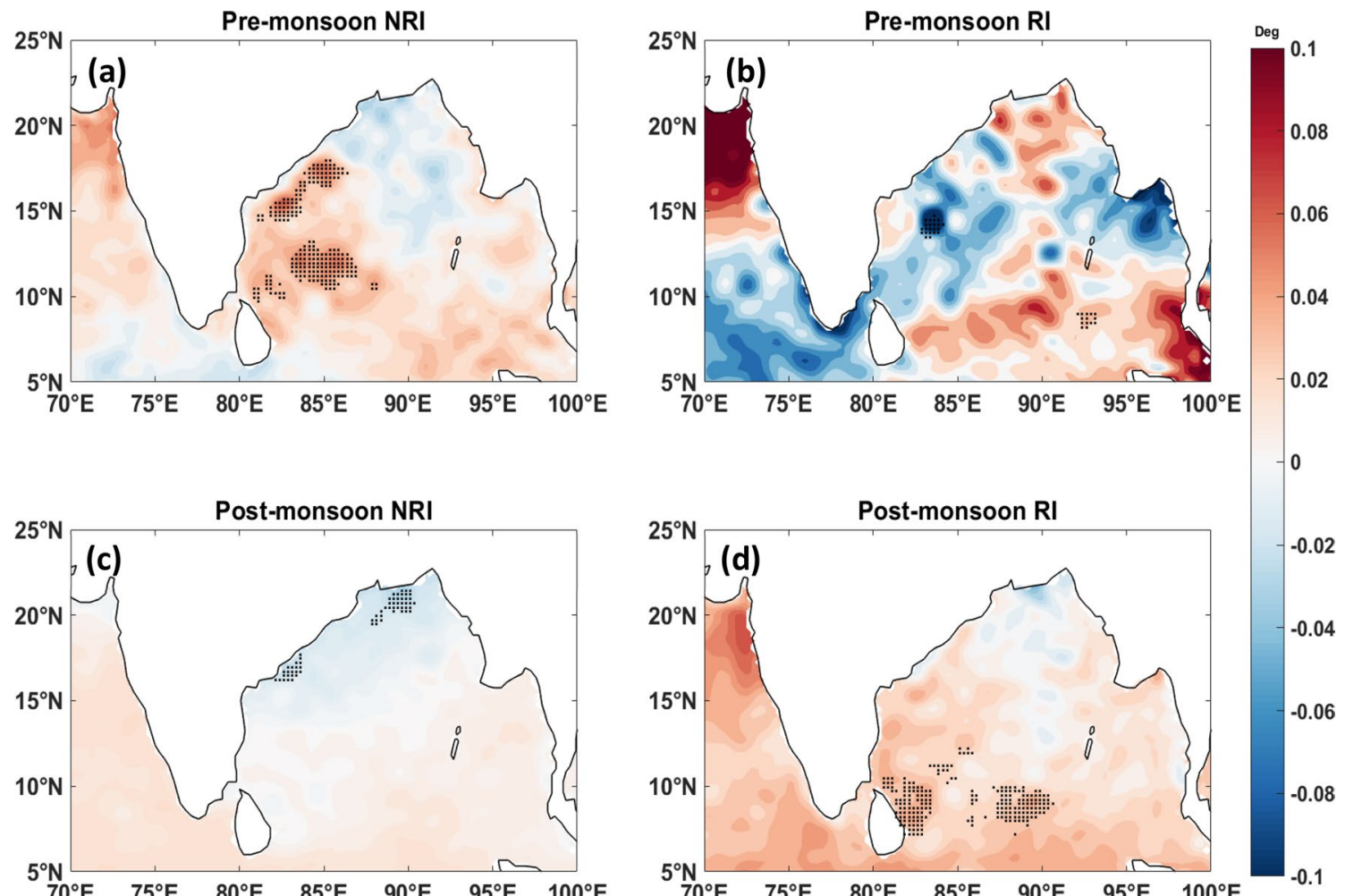

Fig. 10 Same as Fig. 6 but for SST

However, the post-monsoon RI case has exhibited a significant negative anomaly over the Andaman region.

The SST anomaly is analyzed and presented in Fig. 10. The analysis reveals that a cold anomaly (negative) is presented interestingly during the pre-monsoon RI case. In contrast, the Non-RI case exhibited a positive anomaly over the broader significant region. On the other hand, the post-monsoon season Rl case exhibited $90 \%$ significant SST over the $7^{\circ} \mathrm{N}-10^{\circ} \mathrm{N}$ latitude region. Moist static energy (MSE) includes the internal energy, latent energy, and potential energy and draws from the warm waters. The MSE equation is derived from the first law of thermodynamics and can be found in [28]. Figure 11 shows the MSE distribution for Non-RI and RI cases during the pre-monsoon and post-monsoon seasons. Figures $11 \mathrm{a}$, $c$ shows that the pre-monsoon has more MSE of above $120 \mathrm{~kJ} / \mathrm{kg}$ than the post-monsoon season Fig. $11 \mathrm{~b}$, d. The $\mathrm{RI}$ case has exhibited less MSE when compared to the Non-RI case in both the seasons. The analysis of individual terms of the MSE budget (not shown) has revealed the specific humidity term is more dominant in the RI cases followed by the latent heat term. On the other hand, for Non-RI cases, Hydrostatic balance is more prevalent by the local tendency term. The individual TC analysis has been carried out (not shown) by considering the TC Phailin (RI) and TC Helen (Non-RI) cases. The analysis revealed that the abundant moisture availability for TC Phailin with a higher convergence rate could help the rapid intensification. The convergence shows a higher anomaly of $0.6 \times 10^{-5} \mathrm{~s}^{-2}$ from climatology with ample moisture available in the TC environment over ocean and land regions. In contrast, the TC Helen did not have higher moisture and vorticity amounts.

\section{Conclusions}

In this study, a preliminary attempt has been made to understand the climatological characteristics associated with rapidly intensified tropical cyclones over the NIO region. It is a very challenging and multiscale problem to forecast rapid intensity changes in TCs. Therefore, understanding these climatological characteristics would benefit the research and operational community in characterizing the rapid intensity changes well in advance. The conclusions made out of the study are as follows:

- The number of cases in the AS basin is significantly less as compare to the BoB. Results suggest that post-monsoon is a more favorable season for cyclogenesis, and $60 \%-70 \%$ of the cases are in this season. The last $10 y e a r$ trend of RI suggests that there is an increasing trend in the last decade. TC formation is mainly contributed in 

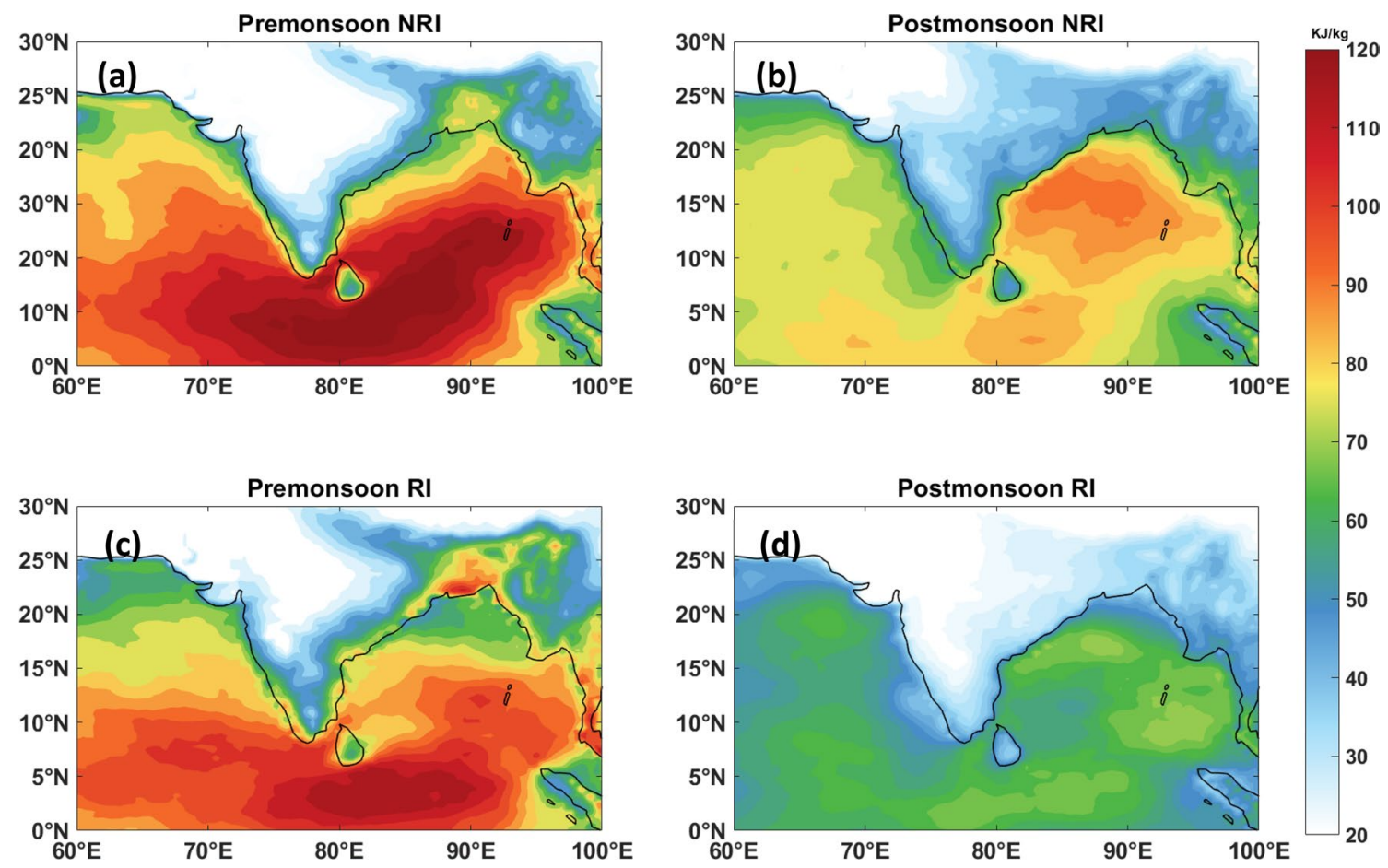

Fig. 11 a Moist static energy for Pre-Monsoon Non Rl events. b, c and $\mathbf{d}$ are same as a but for Post-Monsoon RI, Pre-Monsoon Non RI and Post-Monsoon Rl events, respectively

the range of $82^{\circ} \mathrm{E}-92^{\circ} \mathrm{E}$ and $9^{\circ} \mathrm{N}-15^{\circ} \mathrm{N}$ during the premonsoon season. During the post-monsoon season, longitudes from $84^{\circ} \mathrm{E}$ to $88^{\circ} \mathrm{E}$ hold $68 \%$ of total cases (257 cases out of 374 ). In the case of latitudes, $76 \%$ of TCs are formed between $7^{\circ} \mathrm{N}$ and $13^{\circ} \mathrm{N}$.

- The RI occurrence is more between $9^{\circ} \mathrm{N}$ and $18^{\circ} \mathrm{N}$ and $84^{\circ} \mathrm{E}-93^{\circ} \mathrm{E}$ with a contribution of $92 \%$ and $93 \%$, respectively. During the pre-monsoon season, less RI (37\%) and RD (10\%) cases have been identified than that of the post-monsoon season (RI: $63 \%$ and RD: $90 \%)$. More number of RI and RD cases are observed in the BoB region as compared to the AS region.

- Rapid intensification occurs mostly during the initial stages of the TCs. The rapid intensification also occurs mainly over the oceans only as the typical life period of a TC over the NIO region is $72-120 \mathrm{~h}$.

- India experiences more number of RI TCs landfall (54\%) compared to other NIO rim countries. India's east coast is more vulnerable to landfalling RITCS, especially Tamil Nadu, followed by Andhra Pradesh.

- Significant positive anomalies of vorticity, moisture, convergence, and divergence are dominant in RI cases over the Rl genesis regions. The cyclonic wind circulation is prominent in the RI cases over Non-RI cases.

- The MSE budget analysis revealed that the specific humidity term is more dominant in the RI cases followed by latent heat.
It is a preliminary study to understand the climatology of RI TCs over the $\mathrm{NIO}$ region. Further investigation of $\mathrm{RI}$ changes using high-resolution analysis helps understand the dynamics and thermodynamical processes across the scales (from synoptic to vortex scale).

Acknowledgements The research grant financially supports the work under the National Supercomputing Mission (NSM), MeitY, Govt. of India (CORP: DG:3170). K.K.O. acknowledges the Science and Engineering Research Board (ECR/2016/001637), Govt. of India. The authors sincerely acknowledge the India Meteorological Department for providing the best track data of TCs over the NIO region. European Centre for Medium-Range Weather Forecast (ECMWF) is acknowledged for the high-resolution analysis. Dr. Naveen $\mathrm{G}$ is acknowledged for his help in improving the readability of the manuscript.

\section{Compliance with ethical standards}

Conflict of interest On behalf of all authors, the corresponding author states that there is no conflict of interest.

Open Access This article is licensed under a Creative Commons Attribution 4.0 International License, which permits use, sharing, adaptation, distribution and reproduction in any medium or format, as long as you give appropriate credit to the original author(s) and the source, provide a link to the Creative Commons licence, and indicate if changes were made. The images or other third party material in this article are included in the article's Creative Commons licence, unless indicated otherwise in a credit line to the material. If material is not included in the article's Creative Commons licence and your intended use is not permitted by statutory regulation or exceeds the permitted 
use, you will need to obtain permission directly from the copyright holder. To view a copy of this licence, visit http://creativecommons. org/licenses/by/4.0/.

\section{References}

1. Bhalachandran S, Nadimpalli R, Osuri KK, Marks FD Jr, Gopalakrishnan S, Subramanian S, Niyogi D (2019) On the processes influencing rapid intensity changes of tropical cyclones over the Bay of Bengal. Sci rep 9(1):1-14

2. Busireddy NKR, Nadimpalli R, Osuri KK, Ankur K, Mohanty UC, Niyogi D (2019) Impact of vortex size and Initialization on prediction of landfalling tropical cyclones over Bay of Bengal. Atmos Res Elsevier 224(3):18-29. https://doi.org/10.1016/j. atmosres.2019.03.014

3. Chen H, Gopalakrishnan SG (2015) A study on the asymmetric rapid intensification of Hurricane Earl (2010) using the HWRF system. J AtmosSci 72(2):531-550

4. Fudeyasu H, Ito K, Miyamoto $Y$ (2018) Characteristics of tropical cyclone rapid intensification over the Western North Pacific. J Clim 31(21):8917-8930. https://doi.org/10.1175/ JCLI-D-17-0653.1

5. Gopalakrishnan SG, Osuri KK, Marks F, Mohanty UC (2019) An inner-core analysis of the axisymmetric and asymmetric intensification of tropical cyclones: Influence of shear. MAUSAM 70(4):667-690

6. Gopalakrishnan SG, Goldenberg S, Quirino T, Zhang X, Marks F Jr, Yeh KS, Atlas R, Tallapragada V (2012) Toward improving high-resolution numerical hurricane forecasting: Influence of model horizontal grid resolution, initialization, and physics. Weather Forecast 27:647-666. https://doi.org/10.1175/ WAF-D-11-00055.1

7. Gopalakrishnan SG, Marks F, Zhang X, Bao JW, Yeh KS, Atlas R (2011) The experimental HWRF system: a study on the influence of horizontal resolution on the structure and intensity changes in tropical cyclones using an idealized framework. Mon Weather Rev 139:1762-1784. https://doi.org/10.1175/2010MWR3535.1

8. Levinson DH, Knapp KR, Kruk MC, Howard J, Kossin JP (2010) The International Best Track archive for climate stewardship (IBTrACS) project: overview of methods and Indian Ocean statistics. In Indian ocean tropical cyclones and climate change, Springer, Dordrecht

9. Liu M, Vecchi GA, Smith JA, Knutson TR (2019) Causes of large projected increases in hurricane precipitation rates with global warming. npjClimAtmosSci 2(1):1-5. https://doi.org/10.1038/ s41612-019-0095-3

10. Mohanty UC, Osuri KK, Pattanayak S, Sinha P (2012) An observational perspective on tropical cyclone activity over Indian seas in a warming environment. Nat Hazards 63(3):1319-1335. https://doi.org/10.1007/s11069-011-9810-z

11. Mohanty UC, Nadimpalli R, Mohanty S, Osuri KK (2019) Recent advancements in prediction of tropical cyclone track over north Indian ocean basin. Mausam 70(1):57-70

12. Mohapatra M, Nayak DP, Sharma RP, Bandyopadhyay BK (2013) Evaluation of official tropical cyclone track forecast over north Indian ocean issued by India meteorological department. J Earth SystSci. https://doi.org/10.1007/s12040-013-0291-1

13. Mohapatra M, Sikka DR, Bandyopadhyay BK, Tyagi A (2013) Outcomes and challenges of forecast demonstration project (FDP) on landfalling cyclones over the Bay of Bengal. Mausam 64:1-12

14. Nadimpalli R, Osuri KK, Mohanty UC, Das AK, Kumar A, Sil S, Niyogi D (2019) Forecasting tropical cyclones in the Bay of
Bengal using quasi-operational WRF and HWRF modeling systems: an assessment study. MeteorolAtmosPhys 132(1):1-17

15. Nadimpalli R, Osuri KK, Pattanayak S, Mohanty UC, Nageswararao MM, Prasad SK (2016) Real-time prediction of movement, intensity and storm surge of very severe cyclonic storm Hudhud over Bay of Bengal using high-resolution dynamical model. Nat Hazards 81(3):1771-1795

16. Nadimpalli R, Srivastava A, Prasad VS, Osuri KK, Das AK, Mohanty UC, Niyogi D (2020) Impact of INSAT-3D/3DR radiance data assimilation in predicting tropical cyclone Titli over the Bay of Bengal. IEEE Trans Geosci Remote Sens. https://doi.org/10.1109/ TGRS.2020.2978211

17. Nolan DS (2007) What is the trigger for tropical cyclogenesis? Aust Meteorol Mag 56(4):241-266

18. Osuri KK, Mohanty UC, Routray A, Mohapatra M (2012) The impact of satellite-derived wind data assimilation on track, intensity and structure of tropical cyclones over the North Indian Ocean. Int J Remote Sens 33:1627-1652. https://doi.org/ 10.1080/01431161.2011.596849

19. Osuri KK, Mohanty UC, Routray A, Niyogi D (2015) Improved prediction of bay of bengal tropical cyclones through assimilation of doppler weather radar observations. Mon Weather Rev 143:4533-4560. https://doi.org/10.1175/MWR-D-13-00381.1

20. Osuri KK, Mohanty UC, Routray A, Kulkarni MA, Mohapatra M (2012) Customization of WRF-ARW model with physical parameterization schemes for the simulation of tropical cyclones over North Indian Ocean. Nat Hazards 63:1337-1359. https://doi.org/ 10.1007/s11069-011-9862-0

21. Osuri KK, Mohanty UC, Routray A, Mohapatra M, Niyogi D (2013) Real-time track prediction of tropical cyclones over the North Indian Ocean using the ARW model. J ApplMeteorolClim 52:2476-2492. https://doi.org/10.1175/JAMC-D-12-0313.1

22. Osuri KK, Nadimpalli R, Mohanty UC, Niyogi D (2017) Prediction of rapid intensification of tropical cyclone Phailin over the Bay of Bengal using the HWRF modelling system. Q J R MeteorolSoc 143:678-690. https://doi.org/10.1002/qj.2956

23. Pattanayak S, Mohanty UC, Gopalakrishnan SG (2012) Simulation of very severe cyclone Mala over Bay of Bengal with HWRF modeling system. Nat Hazards 63:1413-1437. https://doi.org/ 10.1007/s11069-011-9863-z

24. Ritchie EA, Holland GJ (1999) Large-scale patterns associated with tropical cyclogenesis in the western Pacific. Mon Weather Rev 127(9):2027-2043

25. Sahoo B, Bhaskaran PK (2016) Assessment on historical cyclone tracks in the Bay of Bengal, east coast of India. Int J Climatol 36(1):95-109

26. Shu S, Ming J, Chi P (2012) Large-scale characteristics and probability of rapidly intensifying tropical cyclones in the western North Pacific Basin. Weather Forecast 27(2):411-423. https://doi. org/10.1175/WAF-D-11-00042.1

27. Wang C, Wang X, Weisberg RH, Black ML (2017) Variability of tropical cyclone rapid intensification in the North Atlantic and its relationship with climate variations. ClimDyn 49(11-12):3627-3645

28. Wing AA, Coauthors (2019) Moist static energy budget analysis of tropical cyclone intensification in high-resolution climate models. J Clim 32:6071-6095. https://doi.org/10.1175/ JCLI-D-18-0599.1

Publisher's Note Springer Nature remains neutral with regard to jurisdictional claims in published maps and institutional affiliations. 